\title{
$(A, m)$-SYMMETRIC COMMUTING TUPLES OF OPERATORS ON A HILBERT SPACE
}

\author{
Muneo Chō And Sid Ahmed Ould Ahmed Mahmoud
}

\begin{abstract}
Let $\mathbf{T}=\left(T_{1}, \cdots, T_{d}\right)$ and $A$ be a commuting $d$-tuple of operators and a positive operator on a complex Hilbert space, respectively. We introduce an $(A, m)$-symmetric commuting tuple of operators and characterize the joint approximate point spectrum of $(A, m)$-symmetric commuting tuple T. Next we introduce an $(A, m)$-expansive symmetric commuting tuple of operators and show basic properties of $(A, m)$-expansive symmetric commuting tuple.
\end{abstract}

Mathematics subject classification (2010): 47A05, 47A10, 47A11.

Keywords and phrases: Hilbert space, symmetric operator, symmetric commuting tuple of operators.

\section{REFERENCES}

[1] J. AgLeR, A disconjugacy theorem for Toeplitz operators, Amer. J. Math. 112 (1990), no. 1, 1-14.

[2] J. Agler, J. W. Helton And M. Stankus, Classification of hereditary matrices, Linear Algebra Appl. 274 (1998), 125-160.

[3] M. F. Ahmadi, Powers of A-m-isometric operators and their supercyclicity, Bull. Malays. Math. Sci. Soc. 39 (3) (2016), 901-911.

[4] J. A. BALL AND J. W. HeLton, Nonnormal dilations, disconjugacy and constrained spectral factorization, Integral Equations Operator Theory 3 (1980), no. 2, 216-309.

[5] T. BERMúdEZ, A. SADDI AND H. ZAWAY, $(A, m)$-Isometries on Hilbert spaces, Linear Algebra and its Applications 540 (2018) 95-111.

[6] М. СhO, H. Motoyoshi And B. N. NAstovska, On the joint spectra of commuting tuples of operators and a conjugation, Functional Analysis, Approximation and Computation 9 (2) (2017), 2126.

[7] J. GleAson, S. Richter, $m$-isometric commuting tuples of operators on a Hilbert space, Integral Equations Operator Theory 56 (2006), no. 2, 181-196.

[8] C. Gu, Examples of $m$-isometric tuples of operators on a Hilbert space, J. Korean Math. Soc. 55 (2018), no. 1, 225-251.

[9] C. Gu, The $(m, q)$-isometric weighted shifts on $l^{p}$ spaces, Integral Equations Operator Theory 82(2015), 157-187.

[10] K. Hedayatian And A. M. Moghaddam, Some properties of the spherical $m$-isometries, J. Operator Theory 79:1(2018), 55-77.

[11] J. W. Helton, Operators with a representation as multiplication by x on a Sobolev space, in Hilbert Space Operators, Colloquia Math. Soc. Janos Bolyai, vol. 5, Tihany, Hungary, 1970, pp. 279-287.

[12] J. W. HeLton, Infinite dimensional Jordan operators and Sturm-Liouville conjugate point theory, Trans. Amer. Math. Soc. 170 (1972), 305-331.

[13] P. H. W. HoffmANn AND M. MACheY, $(m, p)$-Isometric and $(m, \infty)$-isometric operator tuples on normed spaces, Asian-Eur. J. Math. 8(2015), 1550022 (32 pages).

[14] S. JunG, Y. Kim, E. Ko, AND J. E. LeE, On (A,m) -expansive operators, Studia Math., 213(2012), $3-23$.

[15] Y. Kim, E. Ko, AND J. E. LeE, On the Helton class of p-hyponormal operators, Proc. Amer. Math. Soc., 135(2007), 2113-2120.

[16] O. A. MAhmoud Sid Ahmed AND A. SADDI, A-m-Isometric operators in semi-Hilbertian spaces, Linear Algebra and its Applications 436 (2012), 3930-3942. 
[17] O. A. Mahmoud Sid Ahmed, M. Chō And J. E. Lee, On $(m, C)$-isometric commuting tuples of operators on a Hilbert space, Results Math. 73 (2018), no. 2, Art. 51, 31 pp.

[18] S. A. McCullough And L. Rodman, Hereditary classes of operators and matrices, Amer. Math. Monthly, 104(1997), 415-430.

[19] R. Rabaoui And A. SAdDi, On the orbit of an A-m-isometry, Ann. Math. Sil., 26 (2012), 75-91. 